\title{
Anticancer effect of HOTTIP regulates human pancreatic cancer via the metabotropic glutamate receptor 1 pathway
}

\author{
YIBIAO YE ${ }^{1,2}$, YANSHAN LI ${ }^{2,3}$, YUNPING WEI ${ }^{1,2}$, YUNXIUXIU XU ${ }^{1,2}$, RUOMEI WANG ${ }^{1,2}$, ZHIQIANG FU ${ }^{2,4}$,

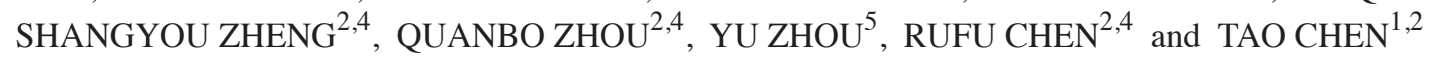 \\ ${ }^{1}$ Department of Hepatobiliary Surgery, Sun Yat-sen Memorial Hospital, Sun Yat-sen University; ${ }^{2}$ Key Laboratory of \\ Malignant Tumor Gene Regulation and Target Therapy of Guangdong Higher Education Institutes; ${ }^{3}$ Department of \\ Blood Transfusion; ${ }^{4}$ Department of Biliary Pancreatic Surgery, Sun Yat-sen Memorial Hospital, \\ Sun Yat-sen University, Guangzhou, Guangdong 510120; ${ }^{5}$ Department of General Surgery, \\ Guangdong General Hospital, Guangzhou, Guangdong 510080, P.R. China
}

Received November 12, 2016; Accepted October 20, 2017

DOI: $10.3892 / \mathrm{ol} .2018 .8870$

\begin{abstract}
The present study aimed to determine how the expression and function of HOTTIP modifies, and regulates the metabotropic glutamate receptor 1 (mGluR1) to affect human pancreatic cancer cell viability. HOTTIP expression was higher in human pancreatic cancer tissue compared with in para-carcinoma tissue. However, downregulation of HOTTIP expression was revealed to significantly reduce cell viability, induce apoptosis, promote caspase- 3 and caspase- 8 activities and increase Bax expression in pancreatic cancer cells. Additionally, downregulation of HOTTIP expression significantly suppressed mGluR1 and mitigated activation of the phosphoinositide 3-kinase (PI3K)/Akt/mechanistic target of rapamycin (mTOR) pathway in pancreatic cancer cells. To the best of our knowledge, the present study is the first to identify that the anticancer effect of HOTTIP against human pancreatic cancer functions the mGluR1 pathway.
\end{abstract}

\section{Introduction}

Pancreatic carcinoma refers to cancer in the pancreatic exocrine secretion and accounts for 8-10\% of all gastrointestinal tumors. The mortality rate associated with pancreatic cancer has been increasing globally. Due to the fact that pancreatic cancer is asymptomatic, it is difficult to diagnose this disease during early stages (1). The 5-year survival rate is only 1-4\% and, with the exception of surgery, there is no clear way of improving the survival of patients with pancreatic cancer (2). Pancreatic

Correspondence to: Professor Tao Chen, Department of Hepatobiliary Surgery, Sun Yat-sen Memorial Hospital, Sun Yat-sen University, 107 Yan Jiang West Road, Guangzhou, Guangdong 510120, P.R. China

E-mail: ct0498@126.com

Key words: HOTTIP, metabotropic glutamate receptor 1, pancreatic cancer, phosphoinositide 3-kinase cancer is not sensitive to traditional chemoradiotherapy (3). Additionally, when using chemotherapeutics to treat pancreatic cancer, chemotherapy resistance and high recurrence rates are two challenges faced in the clinic (4). If the primary tumor is not surgically removed at an early stage, even if patients receive first-line chemotherapy, the median survival rate of pancreatic cancer is only $\sim 8$ months (3).

Long non-coding RNAs (lncRNAs) were originally regarded as the 'noise' of genome transcription and the by-product of RNA polymerase II transcription. IcnRNAs have a transcript length of $>200$ nucleotides and were considered to have no biological function (5). However, more recent research indicates that lncRNAs participate in multiple important regulatory processes, including genome blotting, chromatin modification, transcriptional activation, transcriptional interference and intranuclear transportation (6). Additionally, lcnRNAs are associated with the genesis and development of cancer (6). For example, abnormal lncRNA expression has been observed in colon, breast and liver cancer (7-9). HOTAIR and HOTTIP are two recently identified functional lncRNAs (10). An in vitro experiment indicated that HOTAIR regulates HOXD10 and HOXC11, and that HOTTIP regulates the transcription of HOXA13 (10). Certain studies demonstrate that HOTAIR is abnormally expressed in breast, pancreatic, colon and liver cancer $(5,11)$.

Metabotropic glutamate receptors (mGluRs) belong to the group of G protein-coupled receptors (GPCRs). Despite possessing the same structure, with seven transmembrane domains, mGluRs exhibit amino acid sequences and molecular structures that differ from those of the majority of GPCRs. mGluR1 was separated from other mGluRs early on and is widely distributed in the brain (12). At present, glutamate receptors are widely studied (13). The activation of glutamate receptors may activate multiple signal pathways, two of which are the phosphoinositide 3-kinase (PI3K)/Akt and the mitogen-activated protein kinase (MAPK) pathways (14). The PI3K and Akt signaling pathways serve an important role in regulating cell proliferation, and restraining apoptosis (15). Akt is the serine/threonine protein kinase that regulates cell proliferation and balances apoptosis. 
Increased Akt activity has been observed in a number of types of human cancer, including colon cancer, ovarian cancer, thymic carcinoma and gastric carcinoma, indicating that there is an interaction between Akt and cell proliferation rates (16). The present study attempted to assess the function of HOTTIP in regulating human pancreatic cancer via the mGluR1 pathway.

\section{Materials and methods}

Patient samples. The present study was approved by the Research Ethics Committee of Sun Yat-sen Memorial Hospital (Guangzhou, China) and written informed consent was obtained from all patients (age range 56-67 years, mean $66.55 \pm 9.12$ years; 3 male and 3 female). The pancreatic cancer tissue samples and adjacent non-tumor tissues of 8 patients were available from the Department of Hepatobiliary Surgery, Sun Yat-sen Memorial Hospital from June 2015 to September 2015. All the tissue samples were collected and immediately snap frozen in liquid nitrogen and stored at $-80^{\circ} \mathrm{C}$.

RNA extraction and reverse transcription-quantitative polymerase chain reaction $(P C R)$ analyses. Total RNA was isolated from tissues using TRIzol reagent (Invitrogen; Thermo Fisher Scientific, Inc., Waltham, MA, USA), according to the manufacturer's protocol. cDNA was synthesized with PrimeScript $^{\mathrm{TM}}$ 1st Strand cDNA Synthesis Kit (6110A; Takara Biotechnology Co., Ltd., Dalian, China) at $37^{\circ} \mathrm{C}$ for $60 \mathrm{~min}$ and oligo (dT) primer (Takara Biotechnology Co., Ltd.) according to the manufacturer's protocol. ABI Prism 7500 real-time system (Applied Biosystems; Thermo Fisher Scientific, Inc.) was used, along with a SYBR Premix Ex Taq ${ }^{\mathrm{TM}}$ II kit (Takara Biotechnology Co., Ltd.). The primer sequences were as follows: HOTTIP forward, 5'-CCTAAAGCCACGCTTCTT TG-3' and reverse, 5'-TGCAGGCTGGAGATCCTACT-3'; GAPDH forward, 5'-GTCAACGGATTTGGTCTGTATT-3' and reverse, 5'-AGTCTTCTGGGTGGCAGTGAT-3'. The thermocycling conditions of the PCR were as follows: $94^{\circ} \mathrm{C}$ for $20 \mathrm{sec}, 94^{\circ} \mathrm{C}$ for $15 \mathrm{sec}, 58^{\circ} \mathrm{C}$ for $30 \mathrm{sec}$ to anneal and $72^{\circ} \mathrm{C}$ for $25 \mathrm{sec}$, repeated for 40 cycles. The mRNA expression was quantified using the $2^{-\Delta \Delta \mathrm{Ct}}$ method (17).

Cell culture and cell proliferation assay. The human pancreatic cancer SW1990 cell line was purchased from the Culture Center of Sun Yat-sen University (Guangzhou, China) and was maintained in Dulbecco's modified Eagle's medium (Invitrogen; Thermo Fisher Scientific, Inc.) supplemented with 10\% fetal bovine serum (Gibco; Thermo Fisher Scientific, Inc.), penicillin (100 IU/ml) and streptomycin $(100 \mu \mathrm{g} / \mathrm{ml}$, Sigma-Aldrich; Merck KGaA, Darmstadt, Germany) at $37^{\circ} \mathrm{C}$ in a $5 \% \mathrm{CO}_{2}$ humidified atmosphere. $500 \mathrm{ng}$ of HOTTIP siRNA and the negative control siRNA were purchased from Qiagen GmbH (Hilden, Germany). The siRNA sequences are as follows: HOTTIP, 5'-UGGGAACCCGCUAUUUCACUC UAUU-3'; negative control, 5'-UGACAACUCUUAGGGACC UA-3'. Cells $\left(1 \times 10^{3}\right.$ cell/well) were grown on 96 -well plates until they reached $70 \%$ confluence and were subsequently transfected using Lipofectamine ${ }^{\circledR} 2000$ (Invitrogen; Thermo Fisher Scientific, Inc.). Following transfection for 24, 48 and $72 \mathrm{~h}$, cell proliferation was determined using MTT $(20 \mu 1$,
$50 \mathrm{mg} / \mathrm{kg}$ ) for $4 \mathrm{~h}$. Dimethyl sulfoxide was added to every well and the fluorescence intensity was measured using a fluorescence microplate reader (model no. 680; Bio-Rad Laboratories, Inc., Hercules, CA, USA) at $570 \mathrm{~nm}$.

Assessment of apoptosis by flow cytometry. Following transfection for $48 \mathrm{~h}$, cells were harvested at $1,000 \mathrm{x} \mathrm{g}$ for $10 \mathrm{~min}$ at $4^{\circ} \mathrm{C}$ and washed twice with cold phosphate buffered saline, then resuspended in 1X Binding buffer (Invitrogen; Thermo Fisher Scientific, Inc.). A total of $10 \mu \mathrm{l}$ Annexin V-fluorescein isothiocyanate (Invitrogen; Thermo Fisher Scientific, Inc.) and $5 \mu 1$ propidium iodide (Invitrogen; Thermo Fisher Scientific, Inc.) were added to each cell. Following staining for $15 \mathrm{~min}$ at room temperature, flow cytometry (Beckman Coulter, Inc., Brea, CA, USA) was performed at $488 \mathrm{~nm}$ in order to analyze the rate of apoptosis using Flowjo 7.6.1 (FlowJo LLC, Ashland, OR, USA).

Assessment of caspase-3 and caspase- 8 activities. Cultured cells $\left(1 \times 10^{6}\right.$ cell/well) were lysed in radioimmunoprecipitation assay (RIPA) buffer (Beyotime Institute of Biotechnology, Nanjing, China) and protein was quantified using a bicinchoninic acid (BCA) assay. A total of $10 \mu \mathrm{g}$ protein was incubated with caspase-3 (cat. no. C1116; Beyotime Institute of Biotechnology) and caspase- 8 (cat. no. C1152; Beyotime Institute of Biotechnology) activity kits for $1 \mathrm{~h}$ at $37^{\circ} \mathrm{C}$. The fluorescence intensity was measured using a fluorescence microplate reader (model no. 680; Bio-Rad Laboratories, Inc.) at $450 \mathrm{~nm}$.

Western blot analysis. Cultured cells were lysed in RIPA buffer and protein was quantified using BCA assay. Protein $(50 \mu \mathrm{g})$ was loaded and separated by $10 \%$ SDS-PAGE gel and transferred onto polyvinylidene fluoride (PVDF) membranes. The PVDF membranes were blocked using Tris-Buffered Saline with $0.1 \%$ Tween 20 (TBS-T) buffer containing 5\% skimmed milk at $37^{\circ} \mathrm{C}$ for $1 \mathrm{~h}$ and incubated with primary antibodies against the following: Bax (cat. no. 5023; 1:2,000), mGluR1 (cat. no. 12551; 1:2,000), PI3K (cat. no. 4249; 1:2,000), p-Akt (cat. no., 4060; 1:2,000), p-mTOR (cat. no. 5536; 1:2,000) and GAPDH (cat. no. 2118; 1:5,000; all Cell Signaling Technology, Inc., Danvers, MA, USA) overnight at $4^{\circ} \mathrm{C}$. The membranes were washed three times with TBS-T for $5 \mathrm{~min}$ and incubated with a horseradish peroxidase-conjugated rabbit IgG or mouse IgG secondary antibody (cat. no. sc-2004; 1:5,000; Santa Cruz Biotechnology, Inc., Dallas, TX, USA) for $1 \mathrm{~h}$ at $37^{\circ} \mathrm{C}$. The membrane was visualized using a Plus-ECL kit (PerkinElmer, Inc., Waltham, MA, USA) and quantified using ImageJ 3.0 (ImageJ Software; National Institutes of Health, Bethesda, MD, USA).

Statistical analysis. All data are presented as the mean \pm standard error. Experimental results were assessed using $\chi^{2}$ test, Student's t-test or one-way analysis of variance followed by Tukey's post-hoc test as appropriate. $\mathrm{P}<0.05$ was considered to indicate a statistically significant difference.

\section{Results}

HOTTIP expression in human pancreatic cancer tissue and para-carcinoma tissue. In the present study, HOTTIP 


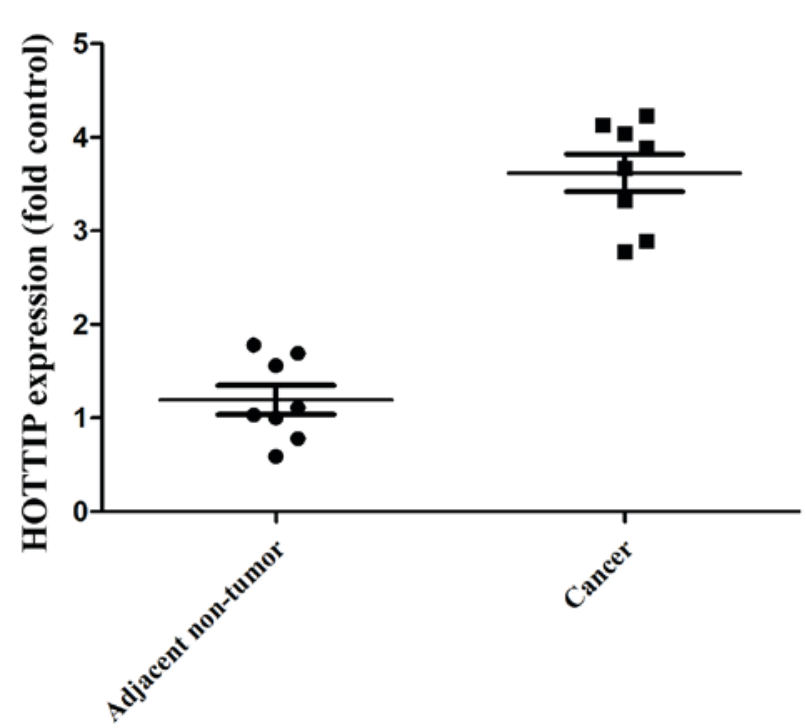

Figure 1. HOTTIP expression in human pancreatic cancer and para-carcinoma tissues.

expression in human pancreatic cancer tissue and para-carcinoma tissue was investigated. As demonstrated in Fig. 1, HOTTIP expression was higher in the human pancreatic cancer tissues compared with that in the para-carcinoma tissues.

Downregulated expression of HOTTIP reduces cell growth and induces apoptosis of pancreatic cancer cells. The effect of HOTTIP on pancreatic cancer cell growth was analyzed. As demonstrated in Fig. 2, compared with negative group, the downregulated expression of HOTTIP reduced cell viability at $48 \mathrm{~h}$ and induced apoptosis of pancreatic cancer cells, compared with the negative group $(\mathrm{P}=0.0032$ and $\mathrm{P}=0.077)$.

Downregulated expression of HOTTIP promotes caspase-3 and caspase- 8 activity, and increases Bax expression in pancreatic cancer cells. The present study also detected the effect of HOTTIP on pancreatic cancer cell apoptosis, caspase- 3 and caspase- 8 activities and Bax expression in pancreatic cancer cell. As demonstrated in Fig. 3, the downregulated expression of HOTTIP promoted caspase- 3 and caspase- 8 activities, Bax protein expression, and suppressed mGluR1, PI3K, p-Akt and p-mTOR protein expression in pancreatic cancer cells.

\section{Discussion}

Pancreatic cancer is an asymptomatic malignant tumor with a high invasive capacity and the majority of patients are diagnosed in middle and advanced stages. The 5-year survival rate is low and prognosis is poor (18). Pancreatic ductal adenocarcinoma is the most common type of pancreatic cancer and presents the highest mortality rate (19). Suppression of apoptosis is an important factor in the genesis and development of pancreatic cancer. Bcl-2 family proteins dominate in the apoptosis and regulation of pancreatic cancer cells. The Bcl-2 family includes apoptosis-inhibiting factors (Bcl-2, Bcl-xL, Bcl-2, Bfl-1, Brag-1, Mcl-1 and A1) and apoptosis-promoting motors (Bax, Bak, Bcl-xS, Bad, Bid, Bik and Hrk) (18). The
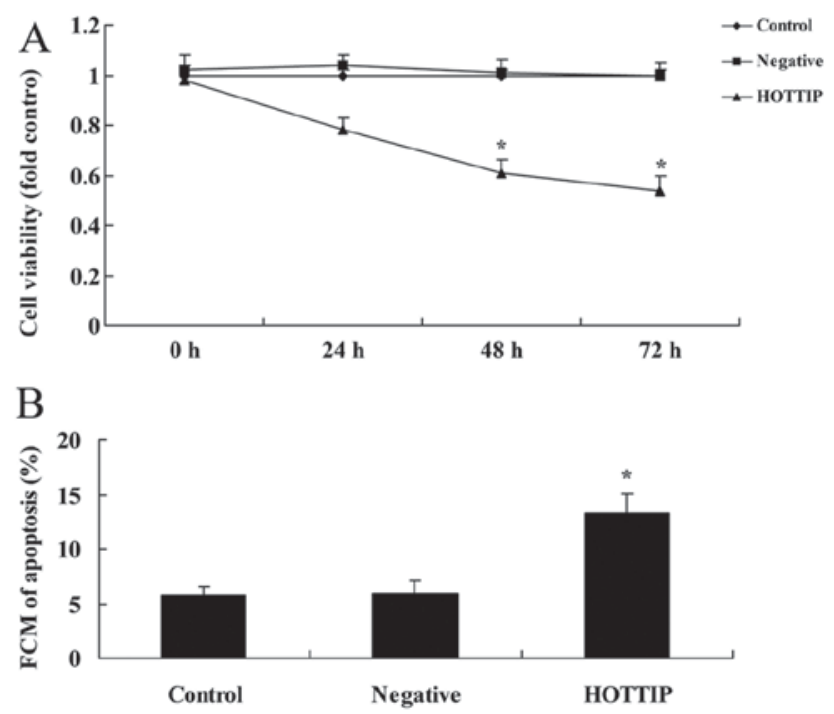

Figure 2. Downregulated expression of HOTTIP reduces cell viability and induces apoptosis of pancreatic cancer cells. Downregulated expression of HOTTIP (A) reduced cell viability and (B) induced apoptosis of pancreatic cancer cells. negative, negative control group; FCM, flow cytometry. ${ }^{*} \mathrm{P}<0.05$ compared with control group.

specific function of them determines whether or not cells undergo apoptosis. To a certain extent, apoptosis or apoptosis inhibition is determined by gene regulation (20).

The mechanism of apoptosis remains unclear, but over time, basic studies on apoptosis have made progress, hypothesizing that the series of ordered cascade reactions associated with apoptosis in cells is able to activate a group of proteases known as caspases (21), which belong to the cysteine protease family (22). Caspase promotes apoptosis, reconstructing the cytoskeleton, terminating DNA repair, destroying DNA and nuclear structure and reducing formation of the apoptotic body (23). Certain studies in biological chemistry and genetics have indicated that the caspase protease family has important functions at every stage of apoptosis $(23,24)$. The results of the present study demonstrated that the downregulated expression of HOTTIP reduced cell viability, induced apoptosis, promoted caspase- 3 and caspase- 8 activity, and increased Bax expression in pancreatic cancer cells. Chen et al (25) demonstrated that the higher expression level of HOTTIP is correlated with positive lymph node metastasis and poor overall survival rates in different types of human cancer.

Certain studies have reported that mGluR1 may hinder apoptosis by activating the PI3K/Akt pathway $(26,27)$. The PI3K/Akt signaling pathway regulates the crucial cellular biological process involved in the genesis and development of cancer, including transcription, translation, metabolism, angiogenesis, apoptosis, proliferation, and regulation of cell cycle progression, migration and invasion of cells $(26,27)$. p-Akt is able to phosphorylate the downstream tyrosine and tryptophan residues, so as to activate downstream factors, cause the apoptosis of suppressor cells, promote cellular proliferation, growth, movement and invasion, and promote tumor angiogenesis (28). In vivo and in vitro experiments have indicated that following restrained activity of the PI3K-Akt signaling 

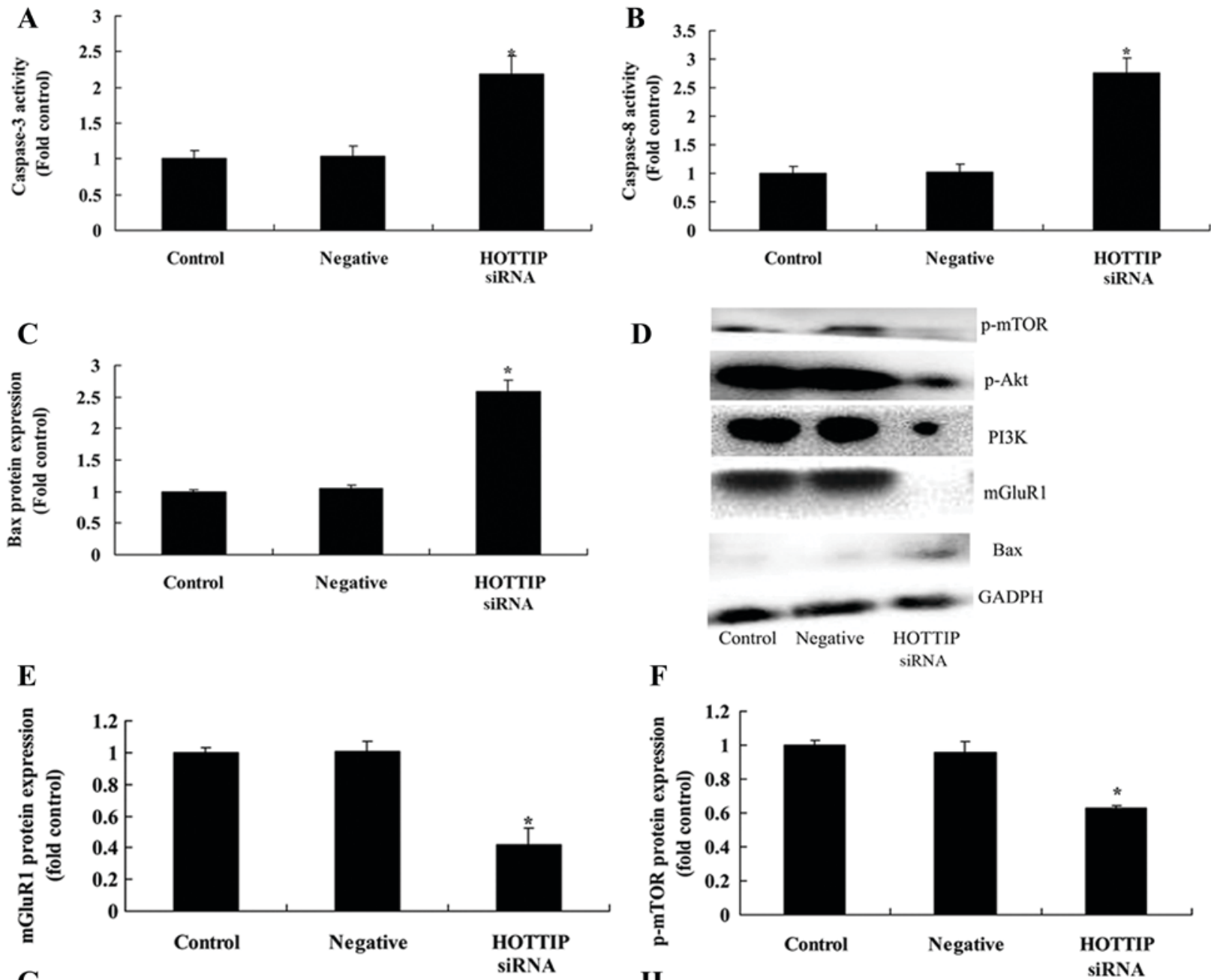

F
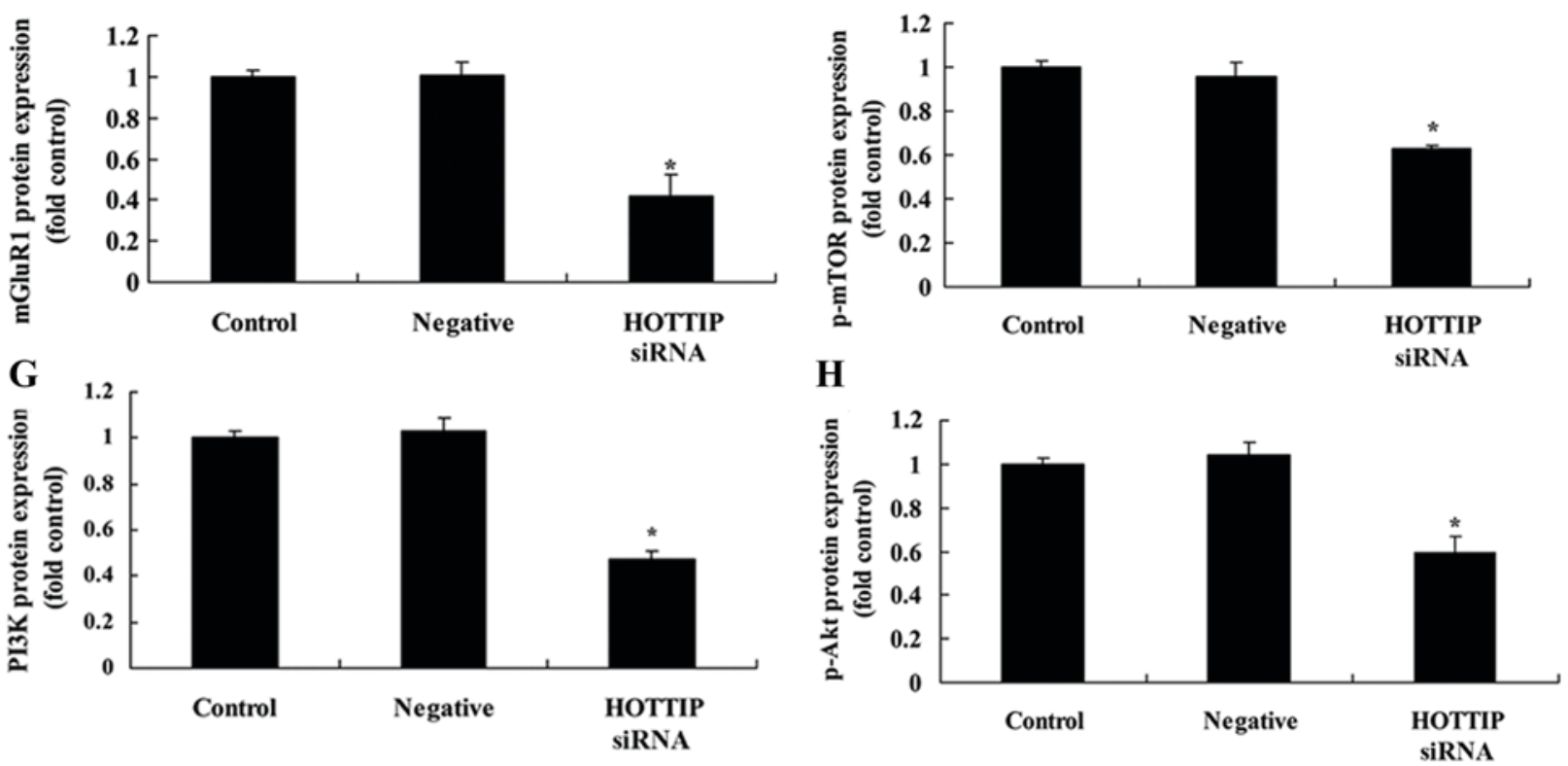

Figure 3. Downregulated expression of HOTTIP promotes caspase-3 and caspase-8 activity and Bax expression, and suppresses mGluR1 and PI3K/Akt/mTOR pathway in pancreatic cancer cells. Downregulated expression of HOTTIP promoted (A) caspase-3 and (B) caspase-8 activities, and (C) Bax, (D) mGluR1, (E) PI3K, (F) p-Akt and (G) p-mTOR expression in pancreatic cancer cells, as determined by statistical analysis and (H) western blot analysis. Bax; B-cell lymphoma 2-like protein 4; mGluR1, metabotropic glutamate receptor 1; PI3K, phosphoinositide 3-kinase; p, phosphorylated; mTOR, mechanistic target of rapamycin; negative, negative control group. ${ }^{*} \mathrm{P}<0.05$ compared with control group.

pathway, pancreatic cancer cells undergo hindered proliferation, promoted apoptosis and reduced invasive ability (29). The present study confirmed that the downregulated expression of HOTTIP suppressed mGluR1 and mitigated activation of the $\mathrm{PI} 3 \mathrm{~K} / \mathrm{Akt} / \mathrm{mTOR}$ pathway in pancreatic cancer cells.

With regards to lncRNAs, HOTAIR is widely studied. By reprogramming the chromosome state to control the expression of numerous genes represented by HOXD10, the functions of HOTAIR may be elucidated (30). Additionally, HOTAIR is associated with breast and liver cancer (30). HOTAIR is markedly reduced in lung cancer tissues, reinforcing the concept that the HOTAIR gene may have an important function in lung cancer (31). HOXD10 is another gene that is associated with cancer (30). Although there is no clear difference in HOXD10 expression in cancerous tissues and healthy tissues, the gene has been revealed to be associated with lymphatic metastasis (32). Additionally, HOXD10 expression has been significantly increased in cancer tissues with lymphatic metastases (31). An in vitro experiment indicated that HOXD10 is modulated by the HOTAIR gene (10).

Taken together, the results of the present study demonstrated that downregulated expression of HOTTIP suppressed mGluR1 and mitigated the activation of the PI3K/Akt/mTOR signaling pathway in pancreatic cancer cells. Therefore, 
HOTTIP, which exhibits a significantly higher expression in human pancreatic cancer tissues compared with that in para-carcinoma tissues, may be a potential drug for the treatment of pancreatic cancer. Additionally, the PI3K/Akt/mTOR pathway may provide potential novel targets for the future treatment of pancreatic cancer.

\section{Acknowledgements}

Not applicable.

\section{Funding}

No funding was received.

\section{Availability of data and materials}

The analyzed data sets generated during the study are available from the corresponding author on reasonable request.

\section{Authors' contributions}

TC designed the experiment; YY, YL, YW, YX, RW, ZF, SZ, QZ, YZ, RC performed the experiments. TC and YY analyzed the data; TC wrote the manuscript.

\section{Ethics approval and consent to participate}

The present study was approved by the Research Ethics Committee of Sun Yat-sen Memorial Hospital (Guangzhou, China). Participants provided written informed consent.

\section{Consent for publication}

Patients provided written informed consent for publication.

\section{Authors' information}

No additional information.

\section{Competing interests}

The authors declare that they have no competing interests.

\section{References}

1. Yu X, Wang Q, Zhou X, Fu C, Cheng M, Guo R, Liu H, Zhang B and Dai M: Celastrol negatively regulates cell invasion and migration ability of human osteosarcoma via downregulation of the PI3K/Akt/NF- $\kappa \mathrm{B}$ signaling pathway in vitro. Oncol Lett 12: 3423-3428, 2016.

2. Cui C and Shi X: miR-187 inhibits tumor growth and invasion by directly targeting MAPK12 in osteosarcoma. Exp Ther Med 14: 1045-1050, 2017.

3. Wang H, Tang M, Ou L, Hou M, Feng T, Huang YE, Jin Y,Zhang H and Zuo G: Biological analysis of cancer specific microRNAs on function modeling in osteosarcoma. Sci Rep 7: 5382, 2017.

4. Su YF, Lin CL, Lee KS, Tsai TH, Wu SC, Hwang SL, Chen SC and Kwan AL: A modified compression model of spinal cord injury in rats: Functional assessment and the expression of nitric oxide synthases. Spinal Cord 53: 432-435, 2015.

5. Liu J, Xiao X, Shen Y, Chen L, Xu C, Zhao H, Wu Y, Zhang Q, Zhong J, Tang Z, et al: MicroRNA-32 promotes calcification in vascular smooth muscle cells: Implications as a novel marker for coronary artery calcification. PLoS One 12: e0174138, 2017.
6. Vishnubalaji R, Hamam R, Yue S, Al-Obeed O, Kassem M, Liu FF, Aldahmash A and Alajez NM: MicroRNA-320 suppresses colorectal cancer by targeting SOX4, FOXM1, and FOXQ1. Oncotarget 7: 35789-35802, 2016.

7. Dou L, Lin H, Wang K, Zhu G, Zou X, Chang E and Zhu Y: Long non-coding RNA CCAT1 modulates neuropathic pain progression through sponging miR-155. Oncotarget 8: 89949-89957, 2017.

8. Wu J, Shuang Z, Zhao J, Tang H, Liu P, Zhang L, Xie X and Xiao X:Linc00152 promotes tumorigenesis by regulating DNMTs in triple-negative breast cancer. Biomed Pharmacother 97: 1275-1281, 2018

9. Cui M, Xiao Z, Wang Y, Zheng M, Song T, Cai X, Sun B, Ye L and Zhang X: Long noncoding RNA HULC modulates abnormal lipid metabolism in hepatoma cells through an miR-9-mediated RXRA signaling pathway. Cancer Res 75: 846-857, 2015.

10. Liu F, Wu L, Wang A, Xu Y, Luo X, Liu X, Hua Y, Zhang D, Wu S, Lin T, et al: MicroRNA-138 attenuates epithelial-to-mesenchymal transition by targeting SOX4 in clear cell renal cell carcinoma. Am J Transl Res 9: 3611-3622, 2017.

11. Zhang F, Liao L, Ju Y, Song A and Liu Y: Neurochemical plasticity of nitric oxide synthase isoforms in neurogenic detrusor overactivity after spinal cord injury. Neurochem Res 36: 1903-1909, 2011.

12. Pu Z, Zhang $X$, Chen Q, Yuan $X$ and Xie H: Establishment of an expression platform of OATP1B1 388GG and 521CC genetic polymorphism and the therapeutic effect of tamoxifen in MCF-7 cells. Oncol Rep 33: 2420-2428, 2015.

13. Barbie TU, Alexe G, Aref AR, Li S, Zhu Z, Zhang X, Imamura Y, Thai TC, Huang Y, Bowden M, et al: Targeting an IKBKE cytokine network impairs triple-negative breast cancer growth. J Clin Invest 124: 5411-5423, 2014.

14. Gokal K, Wallis D, Ahmed S, Boiangiu I, Kancherla K and Munir F: Effects of a self-managed home-based walking intervention on psychosocial health outcomes for breast cancer patients receiving chemotherapy: A randomised controlled trial. Support Care Cancer 24: 1139-1166, 2016.

15. Kalder M, Ky vernitakis I, Albert US, Baier-Ebert M and Hadji P: Effects of zoledronic acid versus placebo on bone mineral density and bone texture analysis assessed by the trabecular bone score in premenopausal women with breast cancer treatment-induced bone loss: Results of the ProBONE II substudy. Osteoporos Int 26: 353-360, 2015.

16. Chirico A, D'Aiuto G, Penon A, Mallia L, DE Laurentiis M, Lucidi F, Botti G and Giordano A: Self-efficacy for coping with cancer enhances the effect of reiki treatments during the Pre-surgery phase of breast cancer patients. Anticancer Res 37: 3657-3665, 2017.

17. Livak KJ and Schmittgen TD: Analysis of relative gene expression data using real-time quantitative PCR and the 2(-Delta Delta C(T)) method. Methods 25: 402-408, 2001.

18. Ren JG, Seth P, Ye H, Guo K, Hanai JI, Husain Z and Sukhatme VP: Citrate suppresses tumor growth in multiple models through inhibition of glycolysis, the tricarboxylic acid cycle and the IGF-1R pathway. Sci Rep 7: 4537, 2017.

19. Zhu H, Dai M, Chen X, Chen X, Qin S and Dai S: Integrated analysis of the potential roles of miRNAmRNA networks in triple negative breast cancer. Mol Med Rep 16: 1139-1146, 2017.

20. Tanaka H, Hazama S, Iida M, Tsunedomi R, Takenouchi H, Nakajima M, Tokumitsu Y, Kanekiyo S, Shindo Y, Tomochika S, et al: miR-125b-1 and miR-378a are predictive biomarkers for the efficacy of vaccine treatment against colorectal cancer. Cancer Sci 108: 2229-2238, 2017.

21. Murphy JP and Pinto DM: Temporal proteomic analysis of IGF-1R signalling in MCF-7 breast adenocarcinoma cells Proteomics 10: 1847-1860, 2010.

22. Kucab JE and Dunn SE: Role of IGF-1R in mediating breast cancer invasion and metastasis. Breast Dis 17: 41-47, 2003.

23. Heskamp S, van Laarhoven HW, Molkenboer-Kuenen JD, Franssen GM, Versleijen-Jonkers YM, Oyen WJ, van der Graaf WT and Boerman OC: ImmunoSPECT and immunoPET of IGF-1R expression with the radiolabeled antibody R1507 in a triple-negative breast cancer model. J Nucl Med 51: 1565-1572, 2010.

24. Li ZH, Xiong QY, Xu L, Duan P, Yang QO, Zhou P and Tu JH: miR-29a regulated ER-positive breast cancer cell growth and invasion and is involved in the insulin signaling pathway. Oncotarget 8: 32566-32575, 2017.

25. Chen Z, He A, Wang D, Liu Y and Huang W: Long noncoding RNA HOTTIP as a novel predictor of lymph node metastasis and survival in human cancer: A systematic review and meta-analysis. Oncotarget 8: 14126-14132, 2017. 
26. Liu C, Liu Z, Li X, Tang X, He J and Lu S: MicroRNA-1297 contributes to tumor growth of human breast cancer by targeting PTEN/PI3K/AKT signaling. Oncol Rep 38: 2435-2443, 2017.

27. Iskender B, Izgi K, Sakalar C and Canatan H: Priming hMSCs with a putative anti-cancer compound, myrtucommulone-a: A way to harness hMSC cytokine expression via modulating PI3K/Akt pathway? Tumour Biol 37: 1967-1981, 2016.

28. Lin Y, Deng W, Pang J, Kemper T, Hu J, Yin J, Zhang J and Lu M: The microRNA-99 family modulates hepatitis B virus replication by promoting IGF-1R/PI3K/Akt/mTOR/ULK 1 signaling-induced autophagy. Cell Microbiol 19, 2017. doi: 10.1111/cmi.12709.

29. Ma Y,Fu S, Lu L and Wang X: Role of androgen receptor on cyclic mechanical stretch-regulated proliferation of $\mathrm{C} 2 \mathrm{C} 12$ myoblasts and its upstream signals: IGF-1-mediated PI3K/Akt and MAPKs pathways. Mol Cell Endocrinol 450: 83-93, 2017.
30. Farr CJ, Easty DJ, Ragoussis J, Collignon J, Lovell-Badge R and Goodfellow PN: Characterization and mapping of the human SOX4 gene. Mamm Genome 4: 577-584, 1993.

31. Wang H, Huo X, Yang XR, He J, Cheng L, Wang N, Deng X, Jin $\mathrm{H}$, Wang N, Wang C, et al: STAT3-mediated upregulation of lncRNA HOXD-AS1 as a ceRNA facilitates liver cancer metastasis by regulating SOX4. Mol Cancer 16: 136, 2017.

32. Tang T, Huan L, Zhang S, Zhou H, Gu L, Chen X and Zhang L: MicroRNA-212 functions as a tumor-suppressor in human non-small cell lung cancer by targeting SOX4. Oncol Rep 38: 2243-2250, 2017. 